\title{
Poética Literária e Poética Cinematográfica: Um Confronto nas Terras Médias de O Hobbit
}

\author{
Vanda de Sousa \& Cristina Ponte \\ Universidade NOVA de Lisboa \\ E-mail: vandamariasousa62@gmail.com/cristina.ponte@fcsh.unl.pt
}

\begin{abstract}
Resumo
Este artigo enquadra-se num estudo mundial sobre audiências da trilogia The Hobbit cujos resultados serão analisados em 2015-2016. Enquadrando e antecipando essa análise dos resultados, o artigo introduz uma das questões de pesquisa: se (e como) é a relação dos espetadores com a adaptação cinematográfica de Peter Jackson marcada pela sua leitura anterior dessa obra literária de J.R.R. Tolkien.

adaptação ao cinema da obra $O$ Senhor dos Anéis, do mesmo autor, e a resposta das audiências a essa trilogia, o artigo confronta a relação da literatura com o cinema, entre a posição tolkieana expressa no ensaio On Fairy-Stories (1938-39) e no conto Leaf by Niggel (1947), por um lado, e as novas possibilidades proporcionadas pelas tecnologias cinematográficas digitais, por outro.
\end{abstract} Apresentando pesquisa anterior relativa à

Palavras-chave: Tolkien; contos de fadas; fantástico; poética literária; cinema digital; audiências de cinema.

\section{Poetic Literature and Film Poetics : A Confrontation in the Midlands of The Hobbit}

\begin{abstract}
This article is part of the global study on the audiences of The Hobbit trilogy, whose results will be analyzed in 20152016. Framing and preparing the further analysis, the article introduces one of the research questions: whether (and how) is the reception of the movie directed by Peter Jackson affected by the previous rea-

ding of the J.R.R. Tolkien's novel. Recalling previous research on the adaptation of Tolkien's novel The Lord of the Rings to the cinema, and its reception ten years ago, the article discusses the relation between literature and cinema, between Tolkien's points of view expressed in $O n$ Fairy-Stories (1939-39) and in the story
\end{abstract}


Leaf by Niggel (1947), on the one hand, and the new possibilities offered by digital cinema technologies, on the other.

Keywords: Tolkien; Fairy Tales; Fantastic; Literary poetic; digital cinema; movie audiences.

\section{O Hobbit uma história para crianças? Um conto de fadas? Uma história fantástica?}

"Num buraco do chão vivia um hobbit. Não se tratava de um buraco húmido, sujo e desagradável, cheio de restos de vermes e com cheiro repugnante, nem tão-pouco de um buraco arenoso, nu e seco, sem nada para uma criatura se sentar ou em que comer: era um buraco de hobbit, e isso significa conforto."

(Tolkien, 2007:12)

$\mathrm{E}^{\mathrm{M}}$ 1958, John Ronald Reuel Tolkien (1892-1973) foi contactado por Forest Ackerman que lhe pediu que lesse a sinopse escrita por Fred Zimmerman com vista a adaptação para cinema da obra $O$ Senhor dos Anéis. Tolkien reagiu negativamente à proposta de adaptação - o que para o escritor era uma história passada num tempo mitológico, em que homens e seres fantásticos se empenhavam numa demanda para destruir o mal, Hollywood interpretava como uma simples história para crianças. E assim se gorou a primeira tentativa para adaptar ao grande ecrã da sala de cinema um texto de Tolkien.

A obra $O$ Senhor dos Anéis teria diversas adaptações para Rádio e Televisão, algumas das quais em vida do escritor (1892-1973). Entre 1955 e 1956, a BBC emitiu uma adaptação da obra para Rádio, em doze partes, das quais nenhuma foi preservada. Em 1981, a BBC voltaria a emitir nova adaptação a Rádio, com a duração de 26 horas e meia. Em 1979, foi a vez de os Estados Unidos produzirem nova adaptação a Rádio; a obra seria preservada em fita magnética e, posteriormente, editada em CD. Para Televisão, em 1980, O Senhor dos Anéis conheceu uma adaptação parcial (O Retorno do Rei); tratava-se de um desenho animado assinado pelos estúdios Rankin-Bass que, em 1977, tinham já produzido uma versão semelhante de $O$ Hobbit. Com um custo de três milhões de dólares, essa versão de $O$ Hobbit tinha como atrativo 
o contar com as vozes de atores como Otto Preminger (Elveking), Richard Boone (Smaug) ou John Huston (Gandalf). O especial televisivo foi adaptado por Romeo Muller e produzido por Arhur Rankin e Jules Bass, tendo sido exibido pela NBC, a 27 de Novembro de 1977, um domingo.

Para Cinema, O Senhor dos Anéis foi adaptado, em 1978, em desenhos animados, por Ralph Bakshi. Nesse ano, Romeo Muller adaptou a Cinema a versão televisiva de $O$ Hobbit e concorreu ao Hugo Award for Best Dramatic Presentation, tendo perdido para o filme Star Wars, escrito e realizado por George Lucas em 1977.

Décadas mais tarde, Peter Jackson, o produtor e realizador neozelandês, relançaria a polémica da adaptação ao Cinema quando, em 2001, estreou a primeira parte de $O$ Senhor dos Anéis ${ }^{1}$, alcançando o que antes era impensável: uma popularidade igual à de Star Wars ou The Godfather ${ }^{2}$. Contudo, permanece a questão de se saber se Tolkien considerava (ou não) a adaptabilidade da (sua) poética literária à poética cinematográfica.

Salvaguardando as características de $O$ Hobbit que diferenciam o texto de $O$ Senhor dos Anéis - uma certa leveza narrativa, traços humorísticos que, posteriormente, quase desaparecem das personagens - embora pudesse ser endereçado a uma literatura infanto-juvenil, Tolkien não considerava este texto como tal. De resto, para o escritor, a literatura não é susceptível de se classificar consoante o público leitor. Para compreender este aspeto, faz-se imperativo que se preste atenção à sua concepção de poética literária e às suas funções junto dos leitores - sejam crianças sejam adultos - para o que se convoca a leitura de duas obras suas: o ensaio On Fairy-Stories (1938-39) e o conto Leaf by Niggel (1947) ${ }^{3}$.

O ensaio On Fairy-Stories, publicado pela primeira vez em 1964, foi escrito no contexto de um conjunto de conferências que Tolkien apresentou na Universidade de St Andrews, Escócia, sobre o escritor escocês Andrew Lang (1844-1912), crítico literário e antropólogo com uma vasta recolha de literatura oral, nomeadamente os contos de fadas (fairy tales). Nesse ensaio, mais

1. O Senhor dos Anéis - A Irmandade do Anel, (2001), adaptado por Fran Walsh, Philippa Boyens e Peter Jackson.

2. The Godfather (1972), adaptado por Mario Puzo, e Francis Ford Coppola a partir do romance homónimo de Mario Puzo, realizado por Francis Ford Coppola.

3. Originalmente publicado na Dublin Review, foi posteriormente publicado em 1964 juntamente com o ensaio On Fairy-stories. 
do que apresentar a sua concepção de contos de fadas enquanto género literário no qual inclui o fantástico, Tolkien apresenta a sua concepção de poética.

Antes de discutirmos essa concepção de poética, adiante, vejamos como se posiciona Tolkien sobre o conceito de fantástico e os contos de fadas. Os estudos sobre a fantasia registaram um especial desenvolvimento no século $\mathrm{XX}$ quer enquanto género, quer abordando-a do ponto de vista da teoria psicanalítica e estruturalista. Em geral, as teorias literárias tendem a considerar o fantástico como género e o conto de fadas como subgénero do fantástico, sendo ainda de considerar a distinção entre high fantasy (que propõe um mundo recriado) e low fantasy (que irrompe num mundo quotidiano).

Enquanto Todorov (1975: 24) apresenta o fantástico como espaço intermediário entre o maravilhoso e o estranho, outros autores colocaram a ênfase na sua relação com a mimese, ou seja, a possibilidade de transformação de elementos ou personagens do real em detentores de características irreais que, todavia, mantêm uma ligação ao real como condição de reconhecimento por parte do leitor. Por exemplo, Attebery (1992: 14) defende que a obra de Tolkien é responsável por uma nova versão de fantástico, que teria conferido uma nova coerência a este género, ainda que atribua esta particularidade à influência dos escritores eduardinos. Jackson (2007: 13) argumenta que Tolkien usa a noção de fantasia como um desejo de algo melhor e mais completo e como uma realidade unificada: a fantasia será o lugar da gratificação. Por sua vez, Brooke-Rose (1981: 63) considera que o fantástico não é tanto um género evanescente mas antes um elemento evanescente e, nesse sentido, assume uma posição mais próxima a Tolkien, para quem o fantástico diz respeito à imaginação e deve ser considerado como um "escape" próprio da condição humana.

Com o vitorianismo, à fantasia e aos contos de fadas tinha sido emprestado um pendor gótico que trazia ao texto os fantasmas, a magia, o pesadelo, o horror, ruínas de antigos castelos, masmorras, correntes e a escuridão, elementos que estão presentes em $O$ Hobbit. Contudo, Tolkien define-o como conto de fadas, em acordo com a definição registada, desde 1750, no Oxford English Dictionary, segundo a qual conto de fadas tem origem no francês conte de fées (expressão com data anterior a 1610). Descrito nesse Dicionário como " $a$ tale about fairies; a tale set in fairyland; any of various a short tales having 
folkloric elements and featuring fantastic or magical events or caracteres" 4 , o conto de fadas é assim localizado num local específico e distante, habitado por seres fantásticos e mágicos, e no qual se vive num perigo iminente.

Os contos de fadas remetem-nos assim para um universo imaginário, maravilhoso, onde ocorrem situações e elementos fora do quotidiano, mágicos e sobrenaturais (Tolkien, 2011: 14). Pode não haver a presença de fadas; antes, faz-se presente uma relação entre a magia e o uso de objetos mágicos, assistese a uma proibição a que o herói será sujeito, ao confronto com vilões com poderes mágicos e à superação da tarefa e ao regresso a casa (Tolkien, 2011: 69).

Para Tolkien, as histórias de fadas reportam-se às origens da linguagem humana, traçando caminhos que nos levam a outros tempos, fora do tempo, a outras geografias, fora do espaço (Tolkien, 2011: 38-39).

A definição tolkieana de contos de fadas distingue-se ainda por o autor não lhes atribuir um público específico. Diversamente de outros autores, Tolkien não pressupõe que os contos de fadas se dirijam, exclusivamente, a crianças ou jovens: contos de fadas são para crianças mas são, igualmente, para adultos, mercê do seu efeito mítico e do apelo ao maravilhoso que sentem tanto as crianças como os adultos. Esse apelo ao maravilhoso é experimentado pelos seres humanos dada a evidência da crença literária, entendida não como lugar ou exercício da suspensão da vontade de saber mas, antes, como pacto entre escritor e leitor; um pacto que permite tomar como verdadeiro o que a narrativa propõe, convocando o leitor para um novo mundo (Tolkien, 2011: 40) quer este seja realista quer seja fantástico.

$\mathrm{Na}$ verdade, trata-se sempre de um mundo imaginado, um mundo secundário que é tomado como verdadeiro sempre que o autor consegue manter a coerência interna do mundo proposto - um mundo construído a partir de novas imagens que não existem senão por via da imaginação, a origem de todos os mundos secundários. A expressão fé poética (poetic faith), cunhada pelo escritor inglês Samuel Coleridge em 1817, significa precisamente o pacto que se estabelece entre o escritor e o leitor quando o texto fantástico é criado, tendo ainda um cunho de interesse humano e vagas ressonâncias com a credibili-

4. In www.oed.com (acedido a 14/12/2014). 
dade; esse pacto permite que o leitor suspenda o seu julgamento relativamente à ausência de plausibilidade da narrativa ${ }^{5}$.

Tendo como base a magia, os contos de fadas não se confundem com a ficção científica que tem, na sua génese, os avanços da ciência; antes se aproximam dos contos populares porque estes se socorrem de personagens estáticas (Reis \& Lopes, 2011: 78-86) e porque cumprem o que Propp recuperou como estrutura característica do conto de fadas: aí as personagens têm como função ajudar ou prejudicar o herói que se vê obrigado a abandonar o lar e a empenhar-se numa demanda (Propp, 1978).

Tomando como ponto de partida o mundo real, os contos de fadas convocam-nos para narrativas que se desenrolam em mundos imaginários que são, a um tempo, estranhos e familiares, como Bettelheim especifica: o conto de fadas narra uma história cuja verdade não é a da causalidade, mas antes, a verdade da nossa imaginação (Bettelheim, 2002:150). Ou seja, a fantasia humana cria histórias de mundos insólitos, mundos invisíveis em que os conflitos se obrigam a ter um final feliz (Tokien, 2011:10).

\section{Da necessidade de um final feliz}

O conto de fadas tem, obrigatoriamente, um final feliz para permitir ao leitor recuperar a capacidade perdida, recuperar a visão mais clara dos acontecimentos, assegurando ao herói, que abandona o lar no início da narrativa, o regresso vitorioso a casa no final, tal como Propp nos demonstrou. Assim, o conto de fadas propõe uma viagem circular ao maravilhoso, durante a qual o herói é posto à prova sendo seu dever a superação e o restabelecimento da ordem perdida (Propp: 1978:108).

Também Tolkien defende que o final feliz é obrigatório, como significa o seu uso do termo eucatástrofe, que é o momento em que se dá a reviravolta feliz. Este termo deriva do grego: eu significa bom, justaposto a catástrofe, que vem de katastrephein. A junção significa, assim, uma boa mudança ou alteração brusca dos acontecimentos. A necessidade deste final feliz prendese com a necessidade do leitor saber que tudo terminará bem: mesmo que o herói seja obrigado a sair do lar, seja vítima das circunstâncias e procure um

5. In Coleridge, Biographia Literaria, 1817, Chapter XIV, vide www.gutenberg.org (acedido em 12/12/2014) 
objeto mágico, no final ele regressará triunfante. É a antecipação deste final feliz que induz, no leitor, o escape.

De acordo com Tolkien, a principal função das histórias de fadas seria a recuperação por via do escape, de cada vez que esta narrativa nos permite a aproximação ao material antigo. Em termos tolkeianos, pelo encontro com o unicórnio somos capazes de constatar a beleza e nobreza de todos os cavalos (Tolkien, 2011). Ou seja, este escape não é alienante: A permanência temporária no mundo secundário promove a sensação de estranhamento que, por contraste, provoca a renovação no mundo primário.

Tolkien não nos propõe a fuga do desertor, essa seria a marca da desistência. Antes, convoca-nos à fuga do prisioneiro, aquele que não se contenta com a sua condição e que procura a libertação. Por oposição, não se dar à fuga é conformar-se com os muros e com as grades que nos trazem reféns do mundo moderno e nos afastam da Natureza, que nos confinam a considerar as duras realidades como insuperáveis (Tolkien, 2011). Aqui reside a necessidade do final feliz nos contos de fadas: só assim nos consolam na libertação, só assim terá lugar a eucatástrofe desta escrita, que se opõe à tragédia. Como escreve:

"A alegria deveria ter exatamente a mesma qualidade, se não mesmo a mesma intensidade, que a proporcionada pelo "momento de viragem" no conto de fadas: essa alegria tem o gosto especial de uma verdade primeira (de outro modo não se chamaria alegria). Ela aponta para a frente (ou para trás, a direção não importa), para a Grande Eucatástrofe. A alegria do Cristianismo, a Glória, é do mesmo tipo; mas é eminentemente (infinitamente, se a nossa capacidade não fosse finita) superior e jubilosa..." 6 (Tolkien, 2011).

6. No original: "The joy would have exactly the same quality, if not the same degree, as the joy which the 'turn' in a fairy-story gives: such joy has the very taste of primary truth (Otherwise its name would not be joy). It looks forward (or backward: the direction in its regard is unimportant) to the GreatEucatastrophe. The Christiann joy, the Gloria, is the same kind; but it is pre-eminently (infinitely, if our capacity were not finite) high and joyous.." (Tolkien, 2011:70). 


\section{Tolkien e a poética pela imaginação versus a poética pelo olhar}

No conto Leaf by Niggel, Tolkien estabelece a ligação com o ensaio On Fairy-Stories, ao usar, em sentido alegórico, a figura da árvore ${ }^{7}$. Neste conto, Niggel é um pintor que começa a sua obra numa única folha. A tela vai crescendo e vai desenvolvendo-se até parecer uma árvore e depois, ocupar todo o enquadramento ao seu redor. E, todavia, Niggel está limitado. Não pelo número de folhas mas pelo seu próprio tempo. É que Niggel deverá, inevitavelmente, fazer uma viagem desagradável, à qual não se pode subtrair. Assim, Niggel está limitado pela perspectiva dessa viagem e pelo tempo em que ela se concretizará. Com essa viagem no seu horizonte temporal, Niggel vai pintando até que se vê na necessidade de se socorrer de uma escada: a sua obra era já maior do que ele. E é então que Niggel decide que a sua obra deve conhecer um fim. Maior do que o seu criador, impossível de terminar antes da viagem a empreender, a obra está, assim, terminada, mas não acabada. A obra transcendeu o olhar do artista, transcendeu os diferentes olhares que se lhe dirigem.

Os olhares são aqui tomados como as diferentes interpretações subjetivas de quem se endereça à obra, na construção da trilogia autor, leitor e obra, que se pode expressar pela trilogia conceptual alegoria, aplicabilidade e símbolo. A alegoria reporta para a significação que está condicionada pela intencionalidade do autor, pelo que o texto perde a capacidade de significação criativa; a aplicabilidade é a interpretação que envolve o leitor e a obra, o elemento do texto que possui diversos significados de forma mais ou menos independente da vontade do autor; e o símbolo reporta-se a um elemento do texto, sendo a sua interpretação gerada tanto pelo autor quanto pelo leitor.

Reencontrando Niggel, a árvore é o símbolo do processo de significação que nunca estará completo, que está em mutação de acordo com as diferentes interpretações emprestadas pelas diferentes subjetividades que a consideram; e a viagem é a morte de cada artista, a morte de cada eu.

O conto Leaf by Niggel possui uma segunda interpretação: reportando para a poética literária, o conto propõe a personagem de um pintor, o que nos transporta para as poéticas com suporte visual. É esta relação que pode ser

7. Em On Fairy-Stories, Tolkien usa a árvore para explicar a origem dos contos de fadas que teriam raízes na linguagem humana, tendo-se desenvolvido em diferentes ramos, contudo, a cada ramo assiste a individualidade, mas também a mesma matriz da qual deriva. 
considerada quando nos interrogamos sobre a legitimidade da adaptação da poética literária da obra de Tolkien à poética cinematográfica: para Tolkien, a narrativa e a arte visual (qualquer que ela seja) não se abrigam sob uma coexistência pacífica. A arte visual, inevitavelmente, direciona a obra literária para o condicionamento visual (representativo e individualizado, atualizado a cada representação e a cada representação individualizado).

Tolkien não se referiu ao cinema, a sua opção foi pelo teatro, tanto no ensaio como no conto. É, contudo, inequívoco que o escritor considerava o teatro, e assim toda a poética que se funda no visual e no imagético, como distante da verdadeira literatura. Considerava que a poética literária tinha de apelar ao primevo, ao original e não ao individualizado, sob pena de não alcançar aplicabilidade. Isto é, para Tolkien, de cada vez que a arte é individualizada, à semelhança do que sucede no teatro, está a impedir-se a aplicabilidade que envolve a obra e o leitor. Como dizia Virginia Woolf no ensaio "The Cinema" (Woolf, 2008: 173), a adaptação da personagem Ana Karenina de Tolstoi impede-nos de imaginarmos a personagem a cada vez que é lida, por cada leitor que a lê. A relação entre o cinema e a literatura é um relacionamento que constrói um espaço que subverte a introspecção propiciada pela poética narrativa.

Por outras palavras, a transposição da poética literária para a poética cinematográfica compromete o carácter ativamente imaginário que o texto literário exige do seu leitor, em contraste com a imposição a que o texto cinematográfico dá lugar: ver o texto cinematográfico promove uma imagem representada no ecrã que acompanhará a leitura posterior; da mesma forma, a leitura anterior pode revelar-se diversa na interpretação de cada sujeito quando comparada com a leitura que o realizador fez do texto literário com vista à sua transposição para texto cinematográfico. Vale dizer que "literatura e cinema constituem, portanto, artes de poética compositiva inerentemente distintas entre si, o que requisita, de seus respetivos estudiosos e apreciadores, a devida atenção às implicações e impactos subsequentes às adaptações" (Vieira, 2013:1726).

A questão da transposição da poética literária para a poética cinematográfica, isto é, a questão da adaptação tal como é reconhecida no seio dos estudos fílmicos, torna-se tanto mais pertinente quanto a poética literária reporta, como no caso das obras de Tolkien, para um mundo imaginário, para personagens, ambientes e temporalidades que não convocam, diretamente, referenciais reais: Bilbo Baggins é um hobbit. Mas já alguém viu um hobbit? 
Como vimos, as personagens que vivem narrativas fantásticas transportam-nos para tempos, espaços e criaturas que não encontram paralelo no quotidiano do leitor. Assim, cabe ao leitor imaginá-las ou visualizá-las, como propõe o investigador britânico Martin Barker (2006), na sua teorização dos resultados do estudo internacional sobre $O$ Senhor dos Anéis, realizado em 2003-2004. Esse estudo, que precede o atual projeto em torno da obra $O \mathrm{Hob}$ bit, teve na sua base um inquérito disponível em 14 línguas e foi respondido por perto de 25 mil espetadores dessa trilogia.

A partir das conclusões alcançadas com esse estudo internacional, Martin Barker cunha uma nova dimensão no conceito de adaptação que, até então, tinha vindo a centrar-se na discussão em torno da fidelidade. Essa nova dimensão propõe-se, agora, travejar no conceito de visualização, enquanto o tornar visível aquilo que, segundo o que era proposto pela poética literária, não teria correspondente real. A figuração da poética cinematográfica permite uma visualização coletiva que, obviamente, pode ser convergente ou divergente com a poética literária quando se consideram segmentos diversos da audiência.

Até um passado recente, os Estudos Fílmicos tenderam a equacionar a questão da adaptação a partir do ponto de vista da fidelidade. Contudo, nos últimos vinte anos, esta abordagem tem vindo a ser questionada, desde logo por Robert Stam (2005). O autor interroga o que se pode entender por fidelidade, levantando a questão do significado ideológico de uma adaptação a par com a questão da eficácia da intertextualidade que está, irremediavelmente, comprometida com o conhecimento dos requisitos das audiências a que se dirige cada adaptação. No próprio projeto em torno da adaptação de $O$ Senhor dos Anéis, Barker já questionava a transposição da poética literária de Tolkien para a poética cinematográfica de Jackson. O investigador travejava a análise na rejeição do pressuposto de que o discurso interior individual supera o nível de percepção e participação social semiótica (Esrock, 1994).

Barker contou quer com as perto de 25 mil respostas aos questionários quer com 300 entrevistas realizadas no âmbito do projeto sobre $O$ Senhor dos Anéis, para este conceito de visualização. Assim, pela interpretação dos questionários que reportavam à transposição da poética literária de Tolkien, no caso específico de $O$ Senhor dos Anéis, para a poética cinematográfica de Jackson, o investigador britânico foi levado a concluir que os Estudos Fílmicos que incidem sobre de adaptação devem incorporar um novo conceito, a visualização. Esta é concebida como gestalt de significados e emoções e já 
não enquanto mera encenação pictórica, que entrevistados revelam quando se referem ao invocar a satisfação (ou não) de ver a representação imagética do que, até então, só podia ter sido representação imaginária, e portanto, subjetiva.

Desta forma, a visualização vai no sentido de uma imaginação partilhada que, inevitavelmente, se traduz num sentimento de pertença e, paradoxalmente, na consciência da identidade individual, de cada vez que o eu reconhece que o outro comungou (ou não) a representação da poética literária. Ou seja, o conceito de visualização a que Barker chegou a partir desse projeto mundial propõe um novo nível de relacionamento entre a poética literária e a poética cinematográfica. Ao invés de convocar a questão da fidelidade ou da identificação através do reconhecimento da partilha do imagético, a visualização dá lugar a uma superação da história. Através da visualização, é possível transpor o imaginário para o lugar do imagético, dando lugar a um significado mais amplo. Barker conclui que este conceito de visualização contribuiu para transformar o modo tradicional de encarar os Estudos Fílmicos sobre Adaptação (2006: 22) como lugar de discussão da transposição do imaginário para o imagético.

\section{Tolkien e o cinema digital}

Desde os seus primórdios que o cinema convoca o imaginário do espectador por via do olhar. Às imagens mais ou menos documentais dos irmãos Lumière, Méliès fez suceder um novo uso da nova tecnologia propondo-se contar histórias como forma de ultrapassar o impasse a que as saídas das fábricas, os comboios a chegarem às gares e os bebés a serem alimentados tinham conduzido o ambiente cinematográfico. Aos sucessivos retratos do quotidiano, Méliès contrapropôs o mise en scéne. Trabalhando a partir de um estúdio, criou os primeiros efeitos especiais do cinema que lhe permitiram convocar a imaginação e ousar para lá do real (Sadoul, 1983: 61).

Foi a partir desta concepção de cinema como lugar e tempo do imaginário que somos chegados à utilização dos novos avanços tecnológicos que imperam no cinema digital e no trabalho de pós-produção. Ou seja, o cinema ganhou definitivamente a sua proposta de contador de histórias, numa sala emersa na escuridão, projetando imagens num grande ecrã, assim reproduzindo o estado onírico mesmo que, como disse Christian Metz (1980: 112), o espectador seja 
um sujeito acordado e o sonhador um homem adormecido. $\mathrm{O}$ espetador sabe que o que vê não é real, é pelo denominado efeito de real que o espectador aceita o pacto narrativo, cria um significado (o que está a ver) e um significante (o que imagina).

As novas tecnologias digitais proporcionam-nos novas imagens e, neste sentido, são o espaço de criação de novos imaginários. Hoje, na era das tecnologias digitais, o cinema ficcional continua a desempenhar a sua função de representação do que não tem equivalente real, continua a ser uma construção imagética e imaginária (Aumont, 2008: 95) ainda que, como defende Christofolli, o cinema digital contribua em especial para esse efeito de sonho de cada vez que nos apresenta e confronta com objetos irreais. Mas se a câmara real nos apresentava narrativas que não eram reais, a questão será, então, a de sabermos o que esperar de uma câmara que não é real.

O cinema de hoje é, tantas vezes, um cinema sem câmara, um cinema de imagens em flash ou em Dreamweaver, criações em 2D ou 3D que não sofreram truncagens ou que foram iludidas num décor sem teto ou profundidade. São imagens idealizadas e desenhadas pela mão humana com o auxílio da computação - nunca viram a luz do dia, nunca saíram de trás de um ecrã. Então cabe perguntar: A fantasia a que a tecnologia cinematográfica de hoje acede poderá interferir nas narrativas cinematográficas? Estar-se-á, hoje, tecnologicamente mais apto a representar o fantástico, conferindo-lhe verosimilhança? Estará, hoje em dia, a tecnologia apta a trazer para a poética cinematográfica o que antes estava, aparentemente, confinado à poética literária? Poderá a tecnologia digital criar novas narrativas, com novos sujeitos que, sendo irreais, ganham realidade por via da tecnologia? Estaremos a assistir a uma nova era no relacionamento entre a literatura e o cinema? A questão está longe de ser consensual.

Não se afastando da proposta tolkieana, em 1969, longe da diversidade de contextos de visionamento do cinema nos dias de hoje, Gollin defendia: "Embora partilhem certos elementos dramáticos, geralmente enfatizadas pelo filme, romances e filmes exigem sensibilidades completamente diferentes. Os romances são lidos por indivíduos concentrados na leitura, lendo ao seu próprio ritmo e capacidade de concentração imaginativa, governados por vozes narrativas ouvidas e escutadas. Um filme é, por outro lado, realizado para o seu público numa sala na semiobscuridade na qual a consciência pública e privada se fundem numa única experiência visual e auditiva intensamente 
compartilhada, movendo os espectadores de acordo com seus próprios ritmos" (Gollin, 1969: 424-425) ${ }^{8}$.

Nos finais da década de 30, no ensaio On Fairy-Stories, Tolkien não referenciou o cinema, ainda que este já se construísse como contador de histórias e produtor de mundos imaginários e imagéticos, até mesmo com aproximações ao fantástico, como seria o caso do expressionismo alemão da década de 1920. Tolkien deixa de fora desta reflexão as artes não miméticas (música e arquitetura), e consagra o seu ponto polémico no que diz respeito à poética e à sua relação com o teatro pautando-se pela proposta aristotélica, em A Poética, que defende que à epopeia cabe o irracional, fonte do maravilhoso, enquanto que na tragédia, o maravilhoso resultaria em cómico.

Com Aristóteles, Tolkien reserva para a poética o maravilhoso que considera, também ele, não se coadunar com a representação em palco - que, à semelhança das imagens cinematográficas, se afasta do mundo interior e onírico da leitura e se aproxima, pela visibilidade conferida pela representação, do mundo primário. Assim, para Tolkien, o teatro (a representação imagética) distingue-se da literatura: o primeiro é o lugar do humano, a segunda é o lugar mais amplo dos contos de fadas, o lugar fantástico, no qual é possível o efeito estético do encantamento (Tolkien, 2011: 60). Lendo a contragosto a sinopse apresentada por Forest Ackerman com vista a adaptação para cinema da obra $O$ Senhor dos Anéis, Tolkien reagiu negativamente à proposta de adaptação, como vimos.

Décadas mais tarde, é a mesma Hollywood que tende a ver no best-seller o blockbuster. A tecnologia digital permitiu a Peter Jackson (re)construir e representar o imaginário fantasioso de Tolkien. Legiões de fãs acorreram aos cinemas. De resto, o escritor havia já renascido por via dos jogos de computador que se inspiravam no seu imaginário. Mas a pergunta permanece: pertence à construção reflexiva de Tolkien a possibilidade de adaptação da sua poética literária a poética cinematográfica?

8. No original: “(...). Though they share certain dramatic elements, usually emphasized by the film, novels and films require altogether different sensibilities. Novels are read by private individuals sunk deep into themselves, responding towards according to their own pace and capacities for imaginative concentration, governed by narrative voices heard and overheard. A film is on the other hand performed on its audiences in a dark place where private and public consciousness merge into a single intensively shared visual and auditory experience, moving its viewers according to its own rhythms" (Gollin, 1969: 424-425). 
Tomando em consideração o acima exposto, e alavancando a reflexão no ensaio, On Fairy-Stories, e no conto Leaf by Niggel, do mesmo autor, então, somos levados a concluir da não legitimidade desta tradução. A representação imagética do texto convoca o espectador no lugar do leitor. Assim, à interioridade da leitura, propõe-se a semiobscuridade da sala de cinema, ou a claridade no download num computador. O mundo imaginado ganha forma, e surge-nos ao olhar. A não tradutibilidade é confirmada no conto Leaf by Niggel.

\section{E no entanto, $O$ Hobbit foi feito filme...}

Nos Estudos de Cinema, a própria teoria da adaptação reconhece que o modo de contar e o modo como o destinatário é convocado, são diferentes quando nos reportamos a um texto literário ou a um texto cinematográfico. A nossa cumplicidade com o texto começa, desde logo, na nossa imaginação e, por isso, aceita-se que as palavras povoam a imaginação de forma mais consistente e prolífica quando comparadas com uma imagem. A imagem mostra-se, não se faz dependente da nossa imaginação: está lá! O pacto narrativo não desaparece. Num certo sentido, mantém-se porque ao espectador continua o pedido que "acredite que é verdade". Também é verdade que a tradução para texto cinematográfico não se quer fiel - nem poderia sê-lo posto que estão a ser considerados meios diferentes (livro e ecrã). Considerando o cinema comercial, convém não descurar que a escolha dos atores e a construção das personagens obedecem a critérios que os tornam comercialmente proveitosos.

No presente caso de $O$ Hobbit, a questão que poderemos ver respondida é se o conceito de visualização a que Martin Barker chegou se mantém: se em O Senhor dos Anéis, a poética cinematográfica propunha uma estrutura narrativa próxima à da poética literária originária, cuja exceção mais marcante é a subtração do núcleo dramático da personagem Tom Bombadil, no presente projeto, The Hobbit, somos confrontados com alterações de plot profundas, introdução de novas personagens e alterações narrativas. A análise dos resultados dos questionários será relevante para clarificar esta nova proposta de transposição já que a poética cinematográfica não segue tão de perto a poética literária original e originária, como sucedeu com a transposição de $O$ Senhor dos Anéis.

Seja no livro, seja no ecrã, a verdade é que lendo ou assistindo, a personagem de Bilbo Baggins nos provoca respostas emocionais. Assim, tanto no 
livro como na sua adaptação cinematográfica assinada por Peter Jackson, $O$ Hobbit apresenta-se em conformidade com o pacto narrativo, ou seja, acreditamos que existe aquele pequeno ser que viveu aquela aventura em tudo tão semelhante à Alegoria da Caverna de Platão: um homem encarcerado, aventura-se e abandona a sua morada, e com isto descobre a verdadeira realidade; também Bilbo vivia numa toca debaixo do chão, levava uma vida tranquila numa comunidade que prezava as convenções, um dia, ele arriscouse a abandonar a tranquilidade da sua morada e aventurou-se numa demanda que lhe permitiu descobrir a sua verdadeira natureza, experimentar um mundo novo e regressar, ainda que passe a ser visto como diferente pelos seus iguais.

Seja no livro, seja no ecrã, seja em conformidade com os desejos de Tolkien, seja em conformidade com as crenças de Peter Jackson, a verdade é que Bilbo ressurgiu e que $O$ Hobbit surge, mais uma vez, quando o mundo dos seus leitores e dos seus espectadores se fragmenta em novos paradigmas, se não agora para a modernidade, já para a hiper-modernidade.

Pouco mais de uma década depois da pesquisa mundial a $O$ Senhor dos Anéis, Martim Barker, juntamente com Matt Hills (Reino Unido) e Ernest Mathijs (Canadá), dirige um novo estudo mundial sobre esta trilogia novamente adaptada e dirigida por Peter Jackson. The World Hobbit Projet reúne agora investigadores de 47 países de todos os continentes, entre os quais Portugal e Brasil. O inquérito dirigido aos espectadores desta trilogia, construído em inglês foi traduzido para 36 línguas. Desde o seu lançamento, em Dezembro de 2014, até meados de Abril de 2015, no momento em que escrevemos estas linhas, tinha sido respondido por mais de 34 mil espectadores, de 157 nacionalidades. ${ }^{9}$

A análise destas respostas, a nível internacional e a nível de cada país, permitirá identificar de que modos é vista esta relação entre a literatura e o cinema por parte dos espectadores de todo o mundo que responderam ao inquérito internacional. Entre as mais de 34 mil respostas que serão analisadas nos próximos meses, perto de mil vieram de espectadores portugueses. De que modos fatores como a sua geração, género, educação, conhecimento prévio ou não da obra literária ou significado do conceito fantasia, entre outros, afetam a sua relação com a adaptação cinematográfica? De que modos

9. Mais informação sobre o projeto e o questionário em www.worldhobbitproject.org 
as condições do fazer cinema digital são experimentadas e expressas por estes espectadores?

\section{Bibliografia}

Aristóteles (1951). Poética. Trad Prof. Eudoro de Souza. Lisboa: Guimarães EditoresImprensa Nacional-Casa da Moeda.

Attebery, B. (1992). Strategies of fantasy. Indiana UP: Bloomington.

Aumont, XX (2008). A Imagem. Edições Texto e Grafia: Lisboa.

Barker, M. (2006). Envisaging 'Visualisation': some challenges from the international Lord of the Rings audience project. Film-Philosophy, The University of Wales, Aberystwyth, 10(3): 1-25, December, www.filmphilosophy.com

Betttelhiem, B. (2002). Psicanálise dos contos de fadas. Trad. Carlos Humberto da Silva. Lisboa: Bertrand Editora.

Brooke-Rose, C. (1983). A rethoric of the unreal: studies in narrative and structure, especially of the Fantastic. Cambridge, London, New York, New Rochelle, Melbourne, Sydney. Cambridge University Press.

Christofolli, E.P. (2010). O Cinema digital como construtor de novos imaginários. Revista rumores, edição 7, 1, janeiro-junho.

Esrock, E.J. (1994). The reader's eye: visual imaging as reader response. Baltimore: Johns Hopkins University Press.

Gollin, M.R. (1969). Film as dramatic literature. College English, 30(6): 424429, Mar. Published by National Council of Teachers of Englisg, acessed 14/1/2011 www.jstor.org

Jackson, R. (2007). Fantasy: the literature of subversion. London, New York: Routledge.

Reis, A. \& Lopes, A.C.M. (2011). Dicionário de Narratologia. Lisboa: Ed. Almedia.

Sadoul, G. (1983) História do Cinema Mundial, I. trad. Manuel Ruas. Lisboa: ed. Livros Horizonte.

Stam, R. \& Raengo, A. (eds.) (2005). Literature through Film: a Guide to the Theory and Practice of Film Adaptation. Oxford: Basil Blackwell. 
Todorov, T. (1975). The Fantastic - a structural approach to a literary genre. Sage House: New York.

Tolkien, J.R. (2007). O Hobbit. Trad. Fernanda Pinto Rodrigues. Lisboa: Edições Europa América.

Tolkien, J.R. (2013). The Hobbit. London: Harper Collins Publishers.

Tolkien, J.R. (2011). Tree and Leaf. London: Harper Collins Publishers.

Vieira, L. (2013). O senhor dos Anéis na literatura e no cinema: Diálogos de artes e imagens, IV encontro nacional de Estudos da Imagem - I Encontro Internacional de Estudos da Imagem 07 a 10 de maio. actas: 1724 -1731. Universidade estadual de Maringá.

Propp, V. (1978). Morfologia do conto. Trad portuguesa Jaime Ferreira e Vitor Oliveira. Lisboa: Editorial Vega.

Woolf, V. (2008). The Cinema in Selected Essays. Oxford: ed. Oxford University Press.

\section{Webgrafia}

www.tolkienlibrary.com (acedido a 14/12/2014)

www.oed.com (acedido a 14/12/2014)

www.gutenberg.org (acedido em 12712/2014)

www.worldhobbitproject.org 